NASA/TM-2004-212902

\title{
Nonlinear Oscillations and Flow of Gas Within Closed and Open Conical Resonators
}

Christopher Daniels

Ohio Aerospace Institute, Brook Park, Ohio

Joshua Finkbeiner and Bruce Steinetz

Glenn Research Center, Cleveland, Ohio

Xiaofan Li and Ganesh Raman

Illinois Institute of Technology, Chicago, Illinois 
Since its founding, NASA has been dedicated to the advancement of aeronautics and space science. The NASA Scientific and Technical Information (STI) Program Office plays a key part in helping NASA maintain this important role.

The NASA STI Program Office is operated by Langley Research Center, the Lead Center for NASA's scientific and technical information. The NASA STI Program Office provides access to the NASA STI Database, the largest collection of aeronautical and space science STI in the world. The Program Office is also NASA's institutional mechanism for disseminating the results of its research and development activities. These results are published by NASA in the NASA STI Report Series, which includes the following report types:

- $\quad$ TECHNICAL PUBLICATION. Reports of completed research or a major significant phase of research that present the results of NASA programs and include extensive data or theoretical analysis. Includes compilations of significant scientific and technical data and information deemed to be of continuing reference value. NASA's counterpart of peerreviewed formal professional papers but has less stringent limitations on manuscript length and extent of graphic presentations.

- TECHNICAL MEMORANDUM. Scientific and technical findings that are preliminary or of specialized interest, e.g., quick release reports, working papers, and bibliographies that contain minimal annotation. Does not contain extensive analysis.

- CONTRACTOR REPORT. Scientific and technical findings by NASA-sponsored contractors and grantees.
- CONFERENCE PUBLICATION. Collected papers from scientific and technical conferences, symposia, seminars, or other meetings sponsored or cosponsored by NASA.

- SPECIAL PUBLICATION. Scientific, technical, or historical information from NASA programs, projects, and missions, often concerned with subjects having substantial public interest.

- TECHNICAL TRANSLATION. Englishlanguage translations of foreign scientific and technical material pertinent to NASA's mission.

Specialized services that complement the STI Program Office's diverse offerings include creating custom thesauri, building customized databases, organizing and publishing research results ... even providing videos.

For more information about the NASA STI Program Office, see the following:

- Access the NASA STI Program Home Page at http://www.sti.nasa.gov

- E-mail your question via the Internet to help@sti.nasa.gov

- Fax your question to the NASA Access Help Desk at 301-621-0134

- Telephone the NASA Access Help Desk at 301-621-0390

- Write to:

NASA Access Help Desk

NASA Center for AeroSpace Information 7121 Standard Drive

Hanover, MD 21076 
NASA/TM-2004-212902

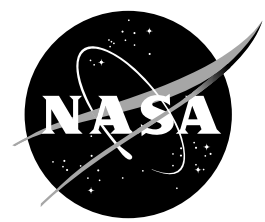

\section{Nonlinear Oscillations and Flow of Gas Within Closed and Open Conical Resonators}

Christopher Daniels

Ohio Aerospace Institute, Brook Park, Ohio

Joshua Finkbeiner and Bruce Steinetz

Glenn Research Center, Cleveland, Ohio

Xiaofan Li and Ganesh Raman

Illinois Institute of Technology, Chicago, Illinois

Prepared for the

42nd Aerospace Sciences Meeting and Exhibit

sponsored by the American Institute of Aeronautics and Astronautics

Reno, Nevada, January 5-8, 2004

National Aeronautics and

Space Administration

Glenn Research Center 
This work was sponsored by the Low Emissions Alternative Power Project of the Vehicle Systems Program at the NASA Glenn Research Center.

Available from

NASA Center for Aerospace Information 7121 Standard Drive

Hanover, MD 21076
National Technical Information Service 5285 Port Royal Road Springfield, VA 22100

Available electronically at http:/ /gltrs.grc.nasa.gov 


\title{
NONLINEAR OSCILLATIONS AND FLOW OF GAS WITHIN CLOSED AND OPEN CONICAL RESONATORS
}

\author{
Christopher Daniels \\ Ohio Aerospace Institute \\ Brook Park, Ohio 44142 \\ Joshua Finkbeiner and Bruce Steinetz \\ National Aeronautics and Space Administration \\ Glenn Research Center \\ Cleveland, Ohio 44135 \\ Xiaofan Li and Ganesh Raman ${ }^{\dagger}$ \\ Illinois Institute of Technology \\ Chicago, Illinois 60616
}

\section{ABSTRACT}

A dissonant acoustic resonator with a conical shaped cavity was tested in four configurations: (A) baseline resonator with closed ends and no blockage, (B) closed resonator with internal blockage, (C) ventilated resonator with no blockage, and (D) ventilated resonator with an applied pressure differential. These tests were conducted to investigate the effects of blockage and ventilation holes on dynamic pressurization. Additionally, the investigation was to determine the ability of acoustic pressurization to impede flow through the resonator. In each of the configurations studied, the entire resonator was oscillated at the gas resonant frequency while dynamic pressure, static pressure, and temperature of the fluid were measured. In the final configuration, flow through the resonator was recorded for three oscillation conditions. Ambient condition air was used as the working fluid. The baseline results showed a marked reduction in the amplitude of the dynamic pressure waveforms over previously published studies due to the use of air instead of refrigerant as the working fluid. A change in the resonant frequency was recorded when blockages of differing geometries were used in the closed resonator, while acoustic pressure amplitudes were reduced from baseline measurements. A sharp reduction in the amplitude of the acoustic pressure waves was expected and recorded when ventilation ports were added. With elevated pressure applied to one end of the resonator, flow was reduced by oscillating the cavity at the fluid fundamental resonant frequency compared to cases without oscillation and oscillation off-resonance.

\footnotetext{
${ }^{*}$ Associate Fellow AIAA, Senior Research Engineer

${ }^{\dagger}$ Associate Fellow AIAA, Associate Professor
}

\section{INTRODUCTION}

The ability to generate high-amplitude pressure waveforms within acoustic resonators has been shown to be highly dependent upon the shape of the cavity. ${ }^{1}$ Researchers ${ }^{1-2}$ have investigated closed resonators of cylindrical, conical, horn-cone, and bulb shape with the interest of their application to refrigeration systems. Their research focused on using R-134a refrigerant as the working fluid ${ }^{1-4}$ and has shown generated pressures exceeding four times that of the ambient fluid at rest. They have shown that high-amplitude pressure generation can be applied to acoustic pumps, compressors, ${ }^{5}$ and thermal management of electronics. ${ }^{6}$ The purpose of this work is to determine whether acoustic pressurization can be used to control or even restrict flow. If possible, this would be the first step toward developing acoustic-based seals.

The study presented herein seeks to evaluate the effects of seal-like features such as central blockages (e.g. shafts), end cap openings (e.g. seal clearances), and pressure differentials on acoustic pressurization. Additional features were added to the baseline resonator investigated to determine the effects of the modifications. In one configuration, a centrally located cylindrical blockage was added to the interior of the resonator for added structural support. Another resonator configuration tested was a modification of the closed resonator to an open resonator with the addition of orifices to each of the two flat ends of the resonator. The final configuration aims to show that the flow of gas through the resonator can be reduced under certain conditions. The objective of this study was to investigate the effects of blockage and ventilation holes on the dynamic pressurization and to investigate the ability of acoustic pressurization to impede flow through a resonator at fluid resonance condition. 


\section{EXPERIMENTAL APPARATUS}

\section{A. Resonator Test Section}

The resonating cavity used in this study had a conical shape, having shape characteristics shown in Figure 1, and was fabricated from aluminum alloy 7075-T6 with a $0.36 \mathrm{~cm}$ (0.14 inch) side wall thickness. End caps were machined from the same material and had minimum thickness of $0.25 \mathrm{~cm}(0.098$ inch). A composite illustration of the resonator supporting the four configurations tested is shown in Figure 2.

\section{1 . Baseline Configuration}

The baseline experimental configuration (referred to as configuration A) consisted of a sealed conical resonator cavity, free from internal obstructions. The total mass of the test section was $4.08 \mathrm{lbm}(1850.7 \mathrm{~g})$.

\section{Conical Resonator With Internal Blockage}

This test section configuration was identical to the baseline configuration except for the addition of a centrally located cylindrical blockage internal to the resonating cavity, referred to as configuration $\mathrm{B}$ in Figure 2. Four different diameter cylinders were individually tested. Each cylinder was manufactured from aluminum alloy 7075-T651 to diameters of 0.403 , $0.423,0.433$, and 0.443 inch $(1.02,1.07,1.10$, and $1.13 \mathrm{~cm})$ and had masses between $0.0843 \mathrm{lbm}(38.3 \mathrm{~g})$ and $0.101 \mathrm{lbm}(45.8 \mathrm{~g})$. The cylinders were mounted inside the resonators with the use of a clearance pilots in the two end caps. The cylinders were manufacturer to a length equal to the resonator plus 0.016 inch $(0.406 \mathrm{~mm})$ to prevent axial movement within the resonator during testing.

\section{Conical Resonator With Ventilation Orifices}

For this configuration, referred to as configuration $\mathrm{C}$ in Figure 2, holes were made in the resonator end caps for ventilation of the otherwise sealed conical resonator. One orifice, 0.102 inch $(0.259 \mathrm{~cm})$ in diameter, was made in the end cap covering the wide end of the resonator. Eight holes of 0.025 inch $(0.635 \mathrm{~mm})$ diameter were drilled on a 0.418 inch $(1.06 \mathrm{~cm})$ diameter bore circle on the narrow end cap. Therefore, the total cross-sectional area of the holes at the wide end of the resonator was 2.0 times the area of the holes at the narrow end of the resonator. The holes in the end caps of the resonator served to ventilate the resonator to the ambient laboratory air. The resonator test section was otherwise free from obstruction.

\section{Conical Resonator With $\Delta \mathrm{p}$ Applied}

The same conical resonator hardware with ventilation orifices was used to determine if flow through the cavity could be reduced. The only modification to the previous setup was metered, pressurized air was applied to the plenum attached to the narrow end of the conical resonator, (referred to as configuration D in Figure 2). The plenum cavity was cylindrical in shape, $(1.25$ inch $(3.18 \mathrm{~cm})$ diameter, 2.49 inch length $(6.32 \mathrm{~cm}))$. In this configuration, no blockages were internal to the resonator.

\section{B. Shaker Table}

An electrodynamic shaker system was used to oscillate the acoustic resonators at the frequencies of interest. The resonators were mounted to the shaker table in order to excite the gas contained in the cavity. A PC-based data acquisition and control system supplied a 0 to 5 Volt sinusoidal voltage to the shaker system's amplifier. The amplifier output signal excited the electrodynamic shaker table to produce a near sinusoidal acceleration of 0 to 100 times that of gravity.

\section{Data Acquisition and Control System}

Both the control of the shaker table oscillation and acquisition of data were completed using a single PC-based program. The oscillation of the shaker table was controlled within $0.001 \mathrm{~Hz}$. The control system was capable of operating in two modes. In the first mode, the frequency of oscillation was swept between a minimum and maximum frequency with discrete frequency steps (generally $1 \mathrm{~Hz}$ or less). The second mode of operation was used to lock on a phase difference between the acceleration and narrow end dynamic pressure signals. This second mode was useful when loitering on the resonant frequency, since the temperature of the gas changed and caused the resonant frequency to shift upward with the speed of sound.

The PC-based system also collected all the temperature, acceleration, static and dynamic pressure measurements. The data was sampled at a rate of 1.25 million samples per second in 12-bit operation. The system was capable of collecting data either on command (when loitering on the resonant frequency) or automatically (when control was in frequency sweep mode).

\section{Instrumentation}

Piezoelectric accelerometers were mounted on the test section and used quartz crystal sensing elements to measure the instantaneous acceleration of the resonator body. The acceleration amplitudes noted in the results section are one half the peak-to-peak measurements of this sensor. Since the acceleration amplitude was controlled manually using the shaker table amplifier, these measurements were accurate to approximately $5 \%$ over the course of a test case. 
The dynamic pressure magnitudes of the acoustic waveforms were recorded using acceleration compensated piezoelectric pressure sensors. The sensors were mounted so as to not protrude into the resonator cavity and disrupt the generated planar waves.

Mounted through the side wall at both the narrow and wide ends, each resonator was instrumented with K-type thermocouples and orifices for static pressure measurements. Care was taken in sizing the length and diameter of the pressure tube between the resonator and the static pressure transducer; the tubes were sized small enough to acoustically filter out the AC-component of the pressure wave, but large enough to capture the rapid changes in the DC-component of static pressure. The orifices diameters were 0.004 inch $(0.102 \mathrm{~mm})$ on the wide end and $0.030 \mathrm{inch}(0.762 \mathrm{~mm})$ on the narrow end of the resonator.

For the last resonator configuration investigated, conical resonator with $\Delta \mathrm{p}$ applied, a 200 SLPM capacity flow meter was attached to the air line supplying the plenum and measured the rate of air flowing through the test section. The error of the measurements for this instrument was calibrated to be less the $1 \%$ of full scale in the range of interest.

\section{RESULTS}

To facilitate comparisons between resonators and between experimental data sets, all of the results are presented in dimensionless form. Since the processes presented by the authors are sensitive to slight variations in fluid static pressure and temperature, the subtle variation in the results would be masked without non-dimensional transformation. The graph axes are

$$
\frac{p}{p_{0}}, \tau, \frac{p_{M A X}}{p_{0}}, \Omega
$$

where $p$ is the total (static plus dynamic) pressure in absolute terms, $p_{M A X}$ is the maximum total pressure recorded during a cycle, $p_{0}$ is the average absolute static pressure of the gas in the non-oscillating resonator before and after the sample was taken. $\Omega$ and $\tau$ are dimensionless frequency and time respectively. The dimensionless variables are defined by

$$
\Omega=\frac{2 \cdot f \cdot l}{\sqrt{\frac{8314 \cdot \gamma \cdot T_{K}}{M W}}}
$$

and

$$
\tau=\frac{f \cdot t}{2 \pi}
$$

where $f$ is the frequency of oscillation, $l$ is the length of the resonator, $\gamma$ is the specific heat ratio of the gas (1.4 for air), $T_{K}$ is the absolute temperature, $M W$ is the average gas molecular weight $(28.964 \mathrm{~kg} / \mathrm{kmol}$ for air), and $t$ is the time.

\section{A. Baseline Configuration}

The baseline resonator was assembled as shown in Figure 2 (configuration A) with the narrow end mounted towards the shaker table. In this configuration, higher acceleration amplitudes were achieved by taking advantage of the compliance of the shaker table mounting hardware. The test section was oscillated at acceleration amplitudes of 20,40,60, and 80 times that of gravity, as measured by the narrow end accelerometer. For each of the acceleration amplitudes, measurements were taken while sweeping oscillation frequencies from below to above fluid resonance in $0.5 \mathrm{~Hz}$ increments. At the highest acceleration amplitude, additional data was collected while decreasing oscillation frequency from above to below resonance.

At frequency increments of $0.5 \mathrm{~Hz}$, the maximum dimensionless pressures recorded at the narrow end of the resonator are plotted in Figure 3. The sweep of frequencies were taken quickly enough as to minimize the amount of heat added to the fluid and therefore minimize the sound speed change, but slowly enough to minimize the effects of transients. The most notable transient was the amount of time required to take static pressure measurement through the acoustic filter orifice. For each of the acceleration amplitudes tested, the maximum pressure rises as the resonant frequency of the fluid is approached. The nonlinear behavior is evident as the resonant frequency shifts upward with increasing acceleration amplitude. At the highest acceleration amplitude, hysteresis is apparent as the resonant frequency is different between incrementally increasing and decreasing.

Figure 4 shows the pressure waveforms at the narrow and wide ends of the resonator. Additionally, the static pressure at the narrow end of the resonator is shown in comparison to the static pressure without oscillation $\left(p / p_{0}=1.0\right)$. The peak-to-peak pressure is larger at the narrow end of the cone resonator than at the wide end. The narrow end pressure waveform is smooth and shows no signs of microshocks. The presence of microshocks would indicate that energy is being dissipated. 
From an original gas temperature of $27.5^{\circ} \mathrm{C}$, a rise in the mean temperature of $\sim 2.9^{\circ} \mathrm{C}$ was recorded between before and after the $80 \mathrm{~g}$ sweep of frequencies plotted in Figure 3. Additionally, differences between air temperatures at each end of the cone resonator were also observed. At the same time the data plotted in Figure 4 was recorded, the gas temperatures at the narrow and wide ends of the conical resonator were $31.0{ }^{\circ} \mathrm{C}$ and $29.2{ }^{\circ} \mathrm{C}$, respectively.

When resonator oscillation frequency approached the fluid resonance, the phase angle between the acceleration and narrow end pressure signals changed rapidly. Figure 5 shows the variation in phase angle during a sweep of frequency at $60 \mathrm{~g}$ acceleration amplitude. The phase angle at peak pressure was 95.3 degrees, but was rapidly dropping before and after the resonant frequency was approached. The data acquisition and control system was capable of holding this phase angle and would therefore maintain the resonant frequency as the input energy would raise the gas temperature thereby increasing the value of resonant frequency.

Upon comparison to the previously published results of Lawrenson et al., ${ }^{1}$ several differences were observed. Lawrenson reported that minimal working fluid heating occurred, so that resonant frequency changes were kept below $0.1 \%$. Our results indicated that fluid heating was significant and such heating would increase the speed of sound $1 \%$ during a typical test cycle. This change in the speed of sound would produce a $13 \mathrm{~Hz}$ increase in the resonant frequency, necessitating the nondimensionalization of the results for comparison.

The hysteresis observed in both the Lawrenson results and the results presented here was approximately the same. The multi-valued frequency response overlaps $4.5 \mathrm{~Hz}$ in Figure 3, whereas Lawrenson's results present an approximate $4.6 \mathrm{~Hz}$ overlap.

Originally the resonator was equipped with a 0.004 inch $(0.102 \mathrm{~mm})$ orifice connecting the working fluid to the static pressure transducer at both ends of the resonator. Since rapid changes in static pressure were recorded at the narrow end of the cone resonator, and these rapid changes required significant amount of time to allow the static pressure transients to reach steady state, the orifice was enlarged to 0.030 inch $(0.76 \mathrm{~mm})$. This allowed for the incremental changes in frequency to occur more rapidly, minimizing the heat addition to the working gas.

\section{B. Conical Resonator With Internal Blockage}

The oscillated test section, shown in Figure 2 (configuration B), was identical to the baseline configuration except for the addition of an internal blockage. The blockage was cylindrical in cross-section with constant diameter at all axial locations. It was fixed within the resonator cavity and could not vibrate undesirably. Four blockages were evaluated having diameters of $0.403,0.423,0.433$, and 0.443 inch $(1.02,1.07,1.10$, and $1.13 \mathrm{~cm})$.

For each of the configurations, the oscillation frequency was increased incrementally in $0.5 \mathrm{~Hz}$ steps until the resonant gas frequency was bounded. Figure 6 shows the frequency response of the gas pressure in the narrow end of the conical resonator. Each of the curves is similar in characteristics. The pressure is single valued at all frequencies indicating no hysteresis was present, though the curves leaned towards higher frequencies demonstrating mild hardening.

The resonant frequency tended to increase with increased blockage diameter. Increased blockage diameter also reduced the maximum pressure obtained from 1.20 to 1.17 by increasing the blockage diameter from 0.403 to 0.443 inch $(1.02$ to $1.13 \mathrm{~cm})$ respectively. The reduction in the maximum pressure can be theoretically linked to the increased thermal and viscous losses caused by the increased surface area of the larger diameter blockages. However, the addition of the larger diameter blockages is more likely further away from the optimum resonator shape in the design space and is being studied further.

\section{Conical resonator with ventilation orifices}

The otherwise closed resonator was opened with the addition of orifices in the resonator end caps, (Figure 2, configuration C). This modification, though minor, had a strong impact on the ability to generate high-amplitude standing waves. The frequency response curve in these conditions is shown in Figure 7 along with the results from the closed resonator experiments. The resonant frequency is similar to that of the closed resonator without internal blockages, but the maximum amplitude of the pressure waves is reduced $75 \%$. The acoustics are considered non-linear even at this reduced pressure amplitudes as the pressures exceeded $10 \%$ overpressure.

\section{Conical Resonator With $\Delta p$ Applied}

In the final configuration, tests were performed to determine whether the acoustic pressurization could reduce flow through the resonator. As shown in Figure 2 (configuration D), metered pressurized air was supplied to the plenum chamber while the pressure drop between the plenum and ambient pressure was measured. To determine a baseline condition, the flow rates were measured at different values of plenum pressurization without oscillating the test section. 
A plot of the pressure differential $(\Delta p)$ between the plenum and the ambient conditions against the flow rate of air though the resonator is shown in Figure 8 as the baseline measurements.

In addition to the baseline measurements taken without resonator oscillations, the test section was oscillated at two frequencies. One frequency corresponded to the fundamental resonant frequency of the gas contained within the resonator. The second frequency was approximately $50 \mathrm{~Hz}$ (or 4\%) lower than the resonant frequency. The flow rate data from each of these conditions is also plotted in Figure 8.

Oscillation of the resonator test section at the resonant frequency reduced the amount of air flowing through the resonator by 5 to $58 \%$ over the differential pressure range investigated, whereas non-resonant oscillations failed to impede the air flow. To confirm this result was a real effect, the apparatus was disassembled and reassembled and the flow resisting behavior was repeated. Note from Figure 8, that when test off-resonance, the flow behavior was identical to the no oscillation case. This is the first known application of non-linear acoustic excitation to restrict flow between high and low pressure cavities. This finding sets the stage for future development of an acoustic-based seal.

\section{CONCLUSIONS}

The use of air as the working fluid reduced the magnitude of the pressure waveforms from those reported by other researchers. The addition of axisymmetric cylindrical blockage to the resonating cavity increased the gas resonant frequency while significantly reducing the acoustic pressures generated. An additional reduction in the generated pressure was observed when the resonator configuration was modified from closed to ventilated. However, when applying a pressure differential across the resonator, the flow of gas was restricted when the cavity oscillation was at the fundamental acoustic resonance frequency as compared to the off-resonance condition. This finding indicated that it is indeed possible to restrict flow using acoustic pressurization and demonstrates initial feasibility for the development of an acoustic-based seal.

\section{REFERENCES}

1. Lawrenson, C.C., Lipkens, B., Lucas, T.S, Perkins, D.K., and Van Doren, T.W., "Measurements of Macrosonic Standing Waves in Oscillating Closed Cavities," J. Acoust. Soc. Am. Vol. 104 (2), Pt. 1, pp. 623-636, Aug. 1998.

2. Ilinskii, Y.A., Lipkens, B., Lucas, T.S., Van Doren, T.W., and Zabolotskaya, E.A. "Nonlinear Standing Waves in an Acoustical Resonator," J. Acoust. Soc. Am. Vol. 104(5), pp. 2664-2674, Nov. 1998.

3. Chun, Y.-D. and Kim, Y.H., "Numerical Analysis for Nonlinear Resonant Oscillations of Gas in Axisymmetric Closed Tubes," J. Acoust. Soc. Am. Vol. 108(6), pp. 2765-2774, Dec. 2000.

4. Li, X., Finkbeiner, J., Raman, G., Daniels, C., and Steinetz, B., "Nonlinear Resonant Oscillations of Gas in Optimized Acoustical Resonators and the Effect of Central Blockage," AIAA Paper 20030368, American Institute of Aeronautics and Astronautics, 41st Aerospace Sciences Meeting, Reno, NV, (2003) and NASA/TM-2003-212019.

5. Lipkens, B., Perkins, D., and LeLande, F., "Introduction to Acoustic Compressors," ASME International Mechanical Engineering Congress and Exposition (2000).

6. Bash, C.E., Patel, C.D., Beitelmal, A., and Burr, R.F., "Acoustic Compression for the Thermal Management of Multi-Load Electronic Systems," Intersociety Conference on Thermal \& Thermomechanical Phenomena in Electronic Systems (2002). 
For $0 \leq \mathrm{z} \leq 0.17[\mathrm{~m}]$,

$\mathrm{r}(\mathrm{z})=0.0056+0.268 \cdot \mathrm{z}[\mathrm{m}]$

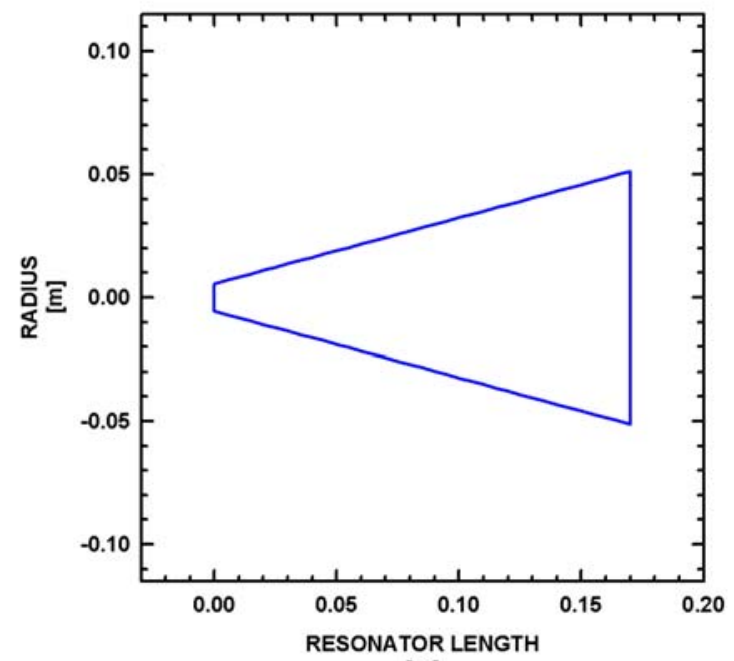

[m]

Figure 1. Contour of the conical resonator.

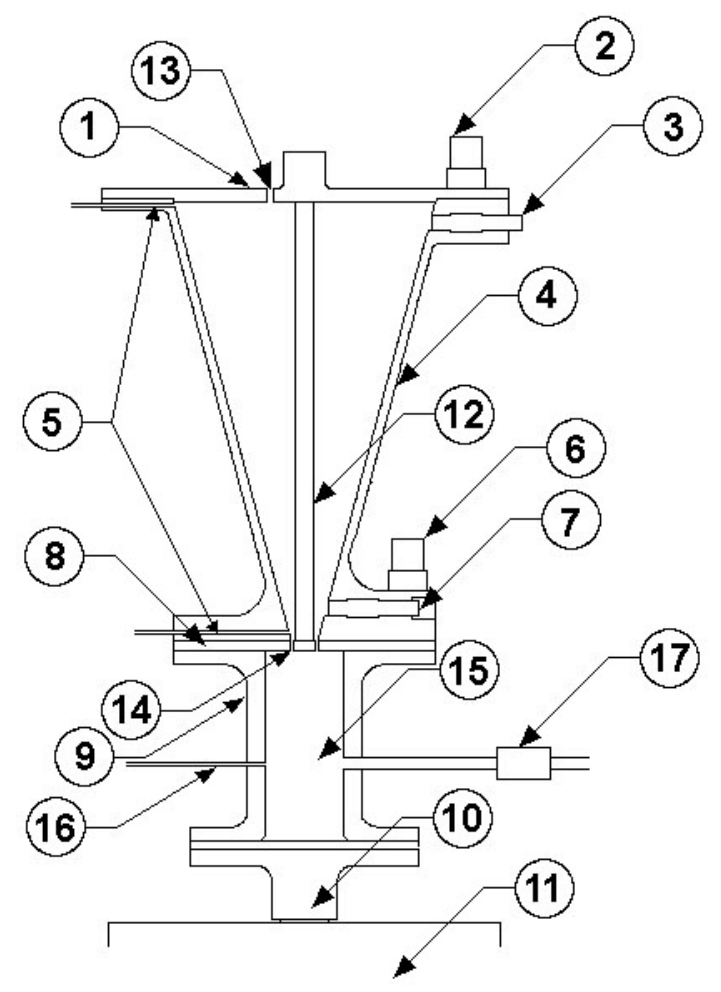

1. Wide end cap

2. Wide end accelerometer

3. Wide end dynamic pressure transducer

4. Acoustic resonator

5. Static pressure and thermocouple ports

6. Narrow end accelerometer

7. Narrow end dynamic pressure transducer

8. Narrow end cap

9. Cylindrical plenum (configuration D only)

10. Attachment to shaker table

11. Electrodynamic shaker

12. Cylindrical blockage (configuration B only)

13. Wide end cap ventilation orifice (configurations $\mathrm{C}$ and D only)

14. Narrow end cap ventilation orifices (configurations $\mathrm{C}$ and $\mathrm{D}$ only)

15. Elevated pressure cylindrical plenum (configuration D only)

16. Static pressure port (configuration D only)

17. Flexible air supply line and flow meter (configuration D only)

Figure 2. Schematic of the acoustic resonator test section in configurations $A$ (closed resonator without blockage), B (closed resonator with blockage), C (open resonator without blockage), and D (open resonator without blockage with pressurized plenum). 


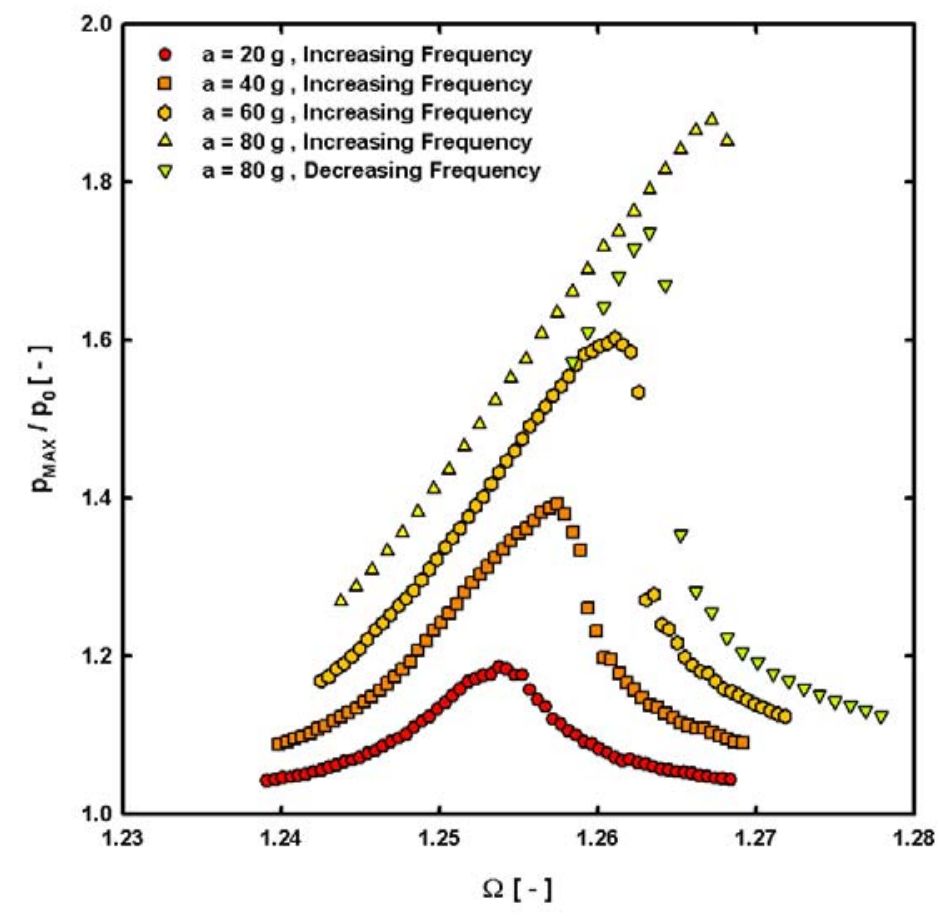

Figure 3. Graph showing the changes in maximum pressure amplitude with varying frequency for a closed conical resonator filled with ambient pressure air at maximum accelerations of $20,40,60$, and 80 times that of gravity.

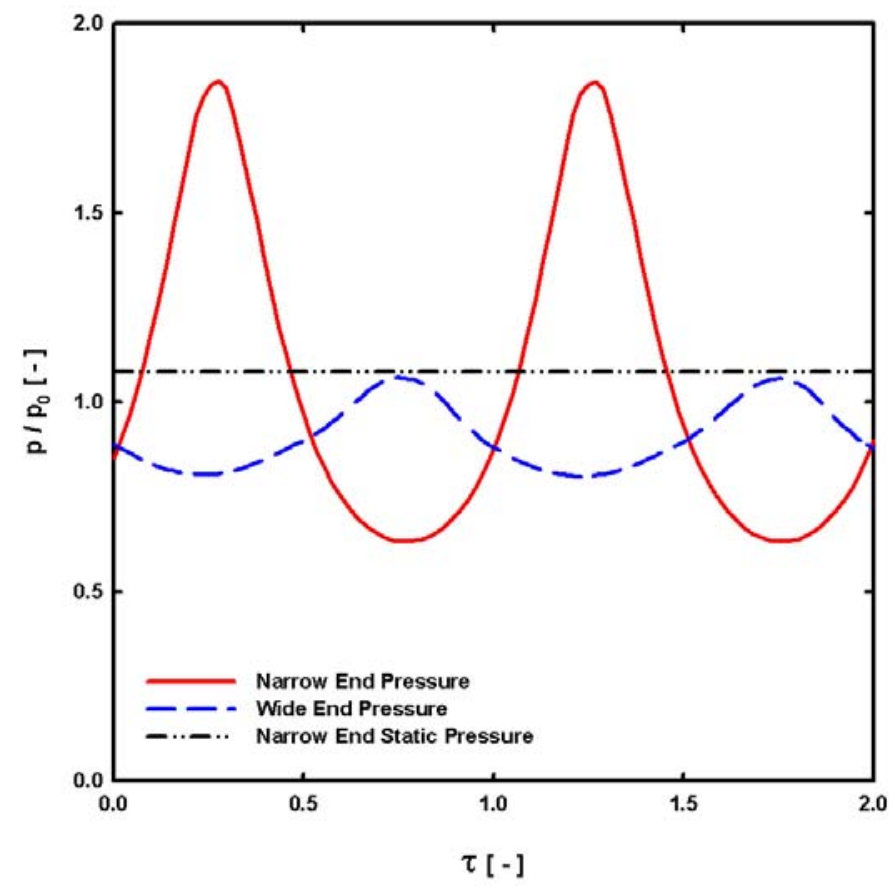

Figure 4. Graph showing the pressure waveforms at the wide and narrow ends of a closed conical resonator filled with ambient pressure air at maximum acceleration of 80 times that of gravity. 


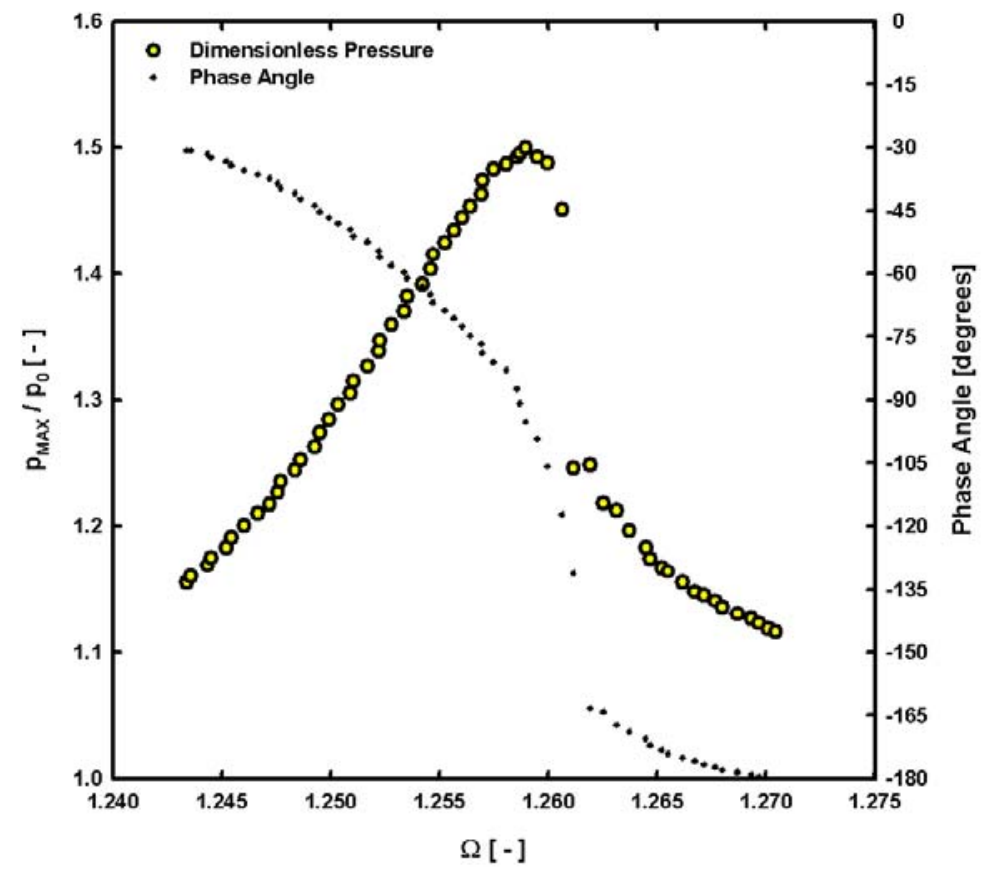

Figure 5. Variation of phase angle (between narrow end acceleration and pressure signals) with frequency and measured narrow end pressure in a closed resonator oscillated at $60 \mathrm{~g}$ acceleration amplitude.

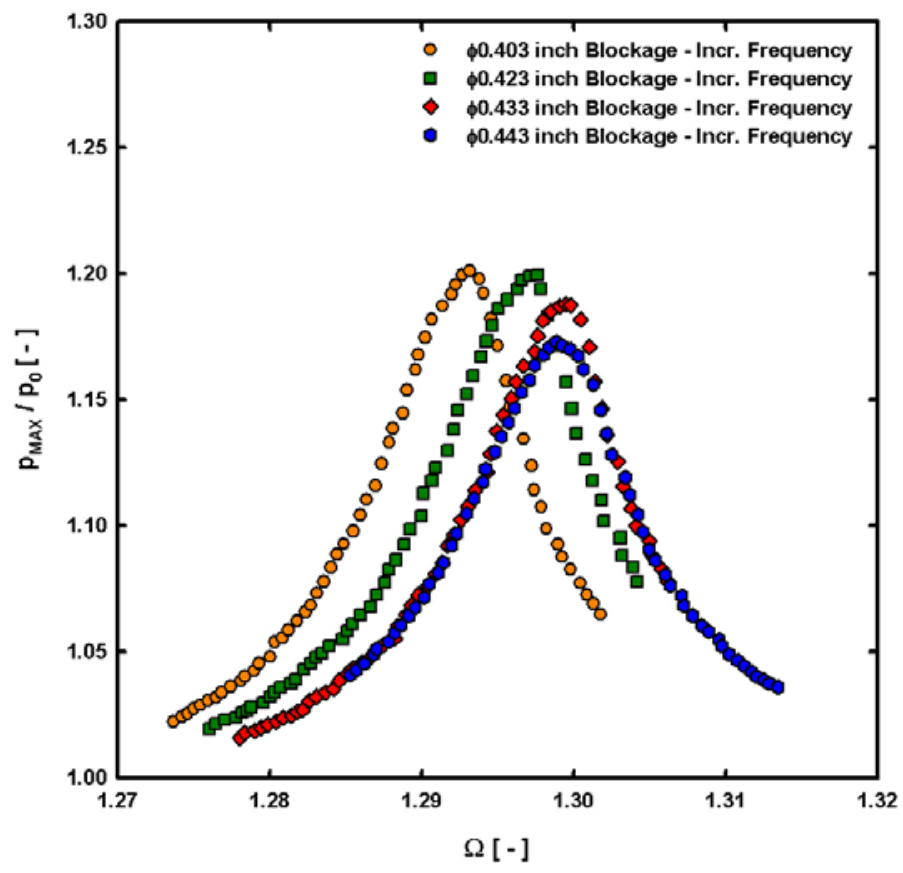

Figure 6. Graph showing the changes in maximum pressure amplitude with frequency for a closed conical resonator with various diameter cylindrical blockages $(\phi 0.403$ inch $(1.02 \mathrm{~cm})$, $\phi 0.423$ inch $(1.07 \mathrm{~cm}), \phi 0.433$ inch $(1.10 \mathrm{~cm})$, and $\phi 0.443$ inch $(1.13 \mathrm{~cm}))$ filled with ambient pressure air at maximum acceleration 80 times that of gravity. 


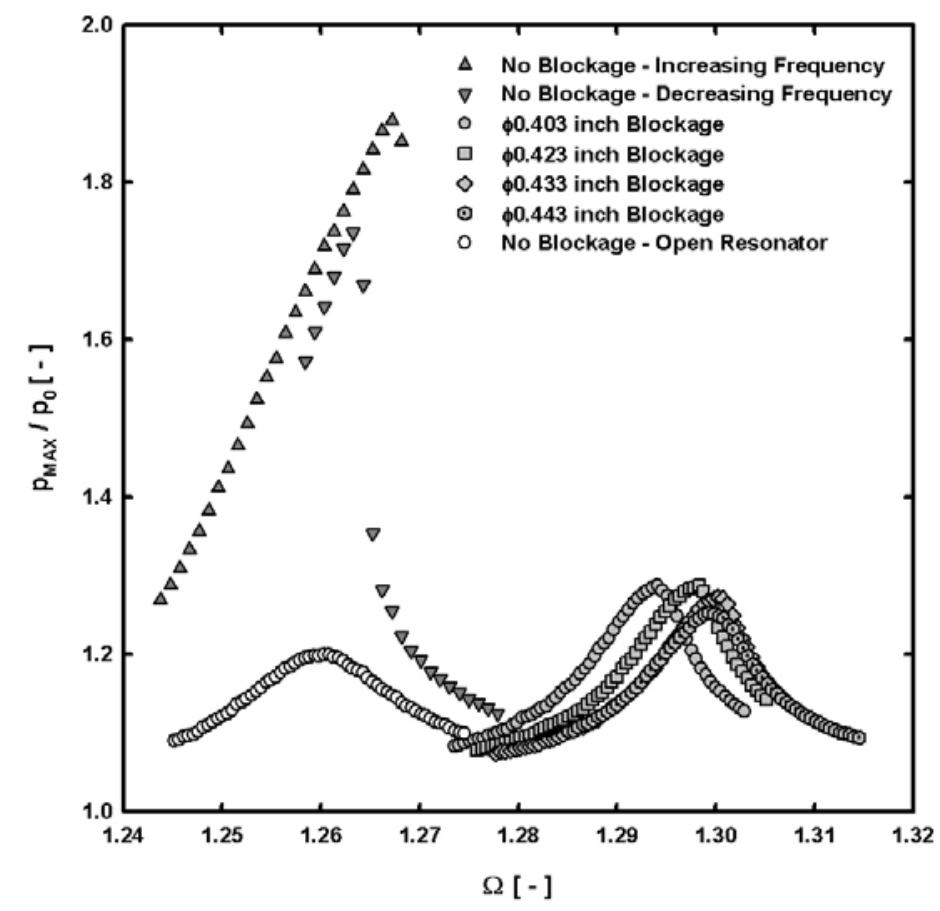

Figure 7. Comparison of the maximum pressure amplitudes between a closed conical resonator with and without cylindrical blockage filled with ambient pressure air at maximum acceleration 80 times that of gravity.

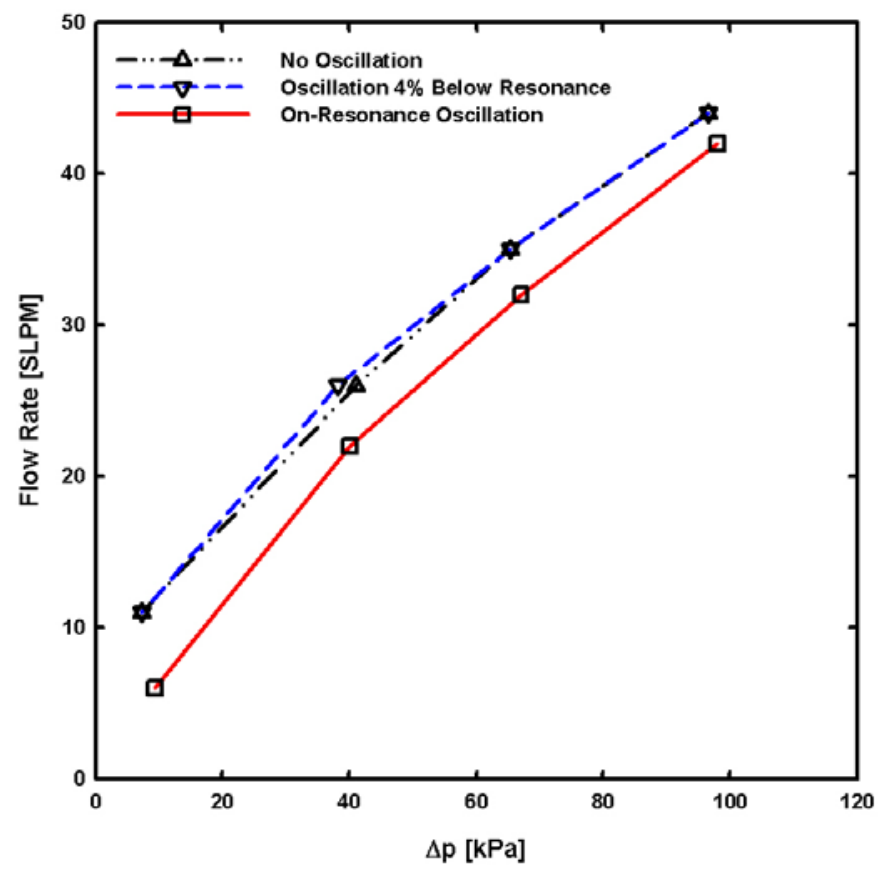

Figure 8. Flow rate through an open conical resonator and the effect of no oscillation, off-resonance oscillation, and on-resonance oscillation of the cavity. 
Public reporting burden for this collection of information is estimated to average 1 hour per response, including the time for reviewing instructions, searching existing data sources, gathering and maintaining the data needed, and completing and reviewing the collection of information. Send comments regarding this burden estimate or any other aspect of this collection of information, including suggestions for reducing this burden, to Washington Headquarters Services, Directorate for Information Operations and Reports, 1215 Jefferson Davis Highway, Suite 1204, Arlington, VA 22202-4302, and to the Office of Management and Budget, Paperwork Reduction Project (0704-0188), Washington, DC 20503.

1. AGENCY USE ONLY (Leave blank) 2. REPORT DATE 3. REPORT TYPE AND DATES COVERED

\section{TITLE AND SUBTITLE}

February 2004

Technical Memorandum

Nonlinear Oscillations and Flow of Gas Within Closed and Open

Conical Resonators

6. AUTHOR(S)

Christopher Daniels, Joshua Finkbeiner, Bruce Steinetz, Xiaofan Li, and Ganesh Raman

7. PERFORMING ORGANIZATION NAME(S) AND ADDRESS(ES)

National Aeronautics and Space Administration

John H. Glenn Research Center at Lewis Field

Cleveland, Ohio 44135-3191
WBS-22-708-28-15

5. FUNDING NUMBERS REPORT NUMBER

E-14325

\section{SPONSORING/MONITORING AGENCY NAME(S) AND ADDRESS(ES)}

National Aeronautics and Space Administration

Washington, DC 20546-0001
10. SPONSORING/MONITORING AGENCY REPORT NUMBER

NASA TM-2004-212902 AIAA-2004-0677

\section{SUPPLEMENTARY NOTES}

Prepared for the 42nd Aerospace Sciences Meeting and Exhibit sponsored by the American Institute of Aeronautics and Astronautics, Reno, Nevada, January 5-8, 2004. Christopher Daniels, Ohio Aerospace Institute, Brook Park, Ohio 44142; Joshua Finkbeiner and Bruce Steinetz, NASA Glenn Research Center; and Xiaofan Li and Ganesh Raman, Illinois Institute of Technology, Chicago, Illinois 60616. Responsible person, Christopher Daniels, organization code 5950, 216-433-6714.

Unclassified - Unlimited

Subject Categories: 07 and 71

Distribution: Nonstandard

Available electronically at http://gltrs.grc.nasa.gov

This publication is available from the NASA Center for AeroSpace Information, 301-621-0390.

\section{ABSTRACT (Maximum 200 words)}

A dissonant acoustic resonator with a conical shaped cavity was tested in four configurations: (A) baseline resonator with closed ends and no blockage; (B) closed resonator with internal blockage; (C) ventilated resonator with no blockage; and (D) ventilated resonator with an applied pressure differential. These tests were conducted to investigate the effects of blockage and ventilation holes on dynamic pressurization. Additionally, the investigation was to determine the ability of acoustic pressurization to impede flow through the resonator. In each of the configurations studied, the entire resonator was oscillated at the gas resonant frequency while dynamic pressure, static pressure, and temperature of the fluid were measured. In the final configuration, flow through the resonator was recorded for three oscillation conditions. Ambient condition air was used as the working fluid. The baseline results showed a marked reduction in the amplitude of the dynamic pressure waveforms over previously published studies due to the use of air instead of refrigerant as the working fluid. A change in the resonant frequency was recorded when blockages of differing geometries were used in the closed resonator, while acoustic pressure amplitudes were reduced from baseline measurements. A sharp reduction in the amplitude of the acoustic pressure waves was expected and recorded when ventilation ports were added. With elevated pressure applied to one end of the resonator, flow was reduced by oscillating the cavity at the fluid fundamental resonant frequency compared to cases without oscillation and oscillation off-resonance.

14. SUBJECT TERMS

Acoustic resonators; Cavity resonators; Oscillators; Sound generators; Standing waves; Seals

\begin{tabular}{|c|c|c|}
\hline $\begin{array}{c}\text { 17. SECURITY CLASSIFICATION } \\
\text { OF REPORT } \\
\text { Unclassified }\end{array}$ & $\begin{array}{c}\text { 18. SECURITY CLASSIFICATION } \\
\text { OF THIS PAGE } \\
\text { Unclassified }\end{array}$ & $\begin{array}{c}\text { 19. SECURITY CLASSIFICATION } \\
\text { OF ABSTRACT } \\
\text { Unclassified }\end{array}$ \\
\hline
\end{tabular}

